\title{
Efeito do processamento e nível de proteína em dietas com milho e soja no desempenho de leitões desmamados(1)
}

\author{
Messias Alves da Trindade Neto(2), Hacy Pinto Barbosa ${ }^{(3)}$, Izabel Marin Petelincar ${ }^{(3)}$ e Eliana Aparecida Schammass ${ }^{(4)}$
}

Resumo - O objetivo deste trabalho foi avaliar o efeito de dietas à base de milho e soja, elaboradas sob diferentes processamentos e níveis de proteína, no desempenho de leitões desmamados. Foram realizados dois experimentos, cada um com 80 leitões, desmamados aos 20 e 18 dias de idade, no primeiro e no segundo experimento, respectivamente. O delineamento experimental foi o de blocos casualizados, em esquema fatorial 2x2, com cinco repetições e quatro animais por parcela. Determinações diárias de ganho de peso, ingestão de alimento e conversão alimentar foram realizadas nos leitões em três fases de desenvolvimento, de acordo com a idade, em ambos os experimentos. Os tratamentos do primeiro experimento consistiram em dois tipos de processamento de milho (comum e pré-gelatinizado) e de soja (farelo de soja e soja integral macerada); no segundo experimento, foram utilizadas dietas com milho pré-gelatinizado e soja integral macerada, contendo ou não produtos lácteos e com níveis protéicos de $18 \%$ e $15 \%$. No primeiro experimento, o milho comum e o farelo de soja propiciaram maior desempenho dos leitões, em todas as fases. No segundo, os leitões apresentaram melhor desenvolvimento quando alimentados com a dieta com produtos lácteos, em todas as fases, e com o nível protéico de $18 \%$, na primeira fase.

Termos para indexação: nível de alimentação, digestibilidade, nutrição animal.

Effect of manufacturing and protein level in diets with corn and soybean on performance of weaned piglets

Abstract - The objective of this study was to evaluate diets with corn and soybean manufactured with different processes and protein levels on weaned piglets performance. Two experiments were carried out, each one with 80 piglets weaned when they were 20 and 18 day-old, in the first and second experiments, respectively. The experiments were in a randomized block design in a $2 \times 2$ factorial scheme, with five replications and four animals per experimental unit. Daily records of weight gain, food ingestion and food conversion were made in piglets in three phases of development, according to piglets age, in both experiments. Treatments of the first experiment used two manufacturing processes in corn (common and pre-cooking) and in soybean (meal and macerated full fat); the second experiment consisted of diets with pre-cooking corn and macerated full fat soybean, containing or not milk by-products and $18 \%$ and $15 \%$ protein level. In the first experiment, common corn and soybean meal allowed better performance of piglets in all phases. In the second experiment, milk by-product diets showed the best results, in all phases, and the $18 \%$ crude protein allowed higher piglets performance on the first phase.

Index terms: feeding level, digestibility, animal nutrition.

\section{Introdução}

Em média, o leitão lactente mama 16 vezes ao dia e a substituição satisfatória desse alimento, alta-

\footnotetext{
(1) Aceito para publicação em 22 de novembro de 2002.

(2) Universidade de São Paulo, Fac. de Medicina Veterinária e Zootecnia, Dep. de Nutrição e Produção Animal, CEP 13635-900 Pirassununga, SP. E-mail: trindadeneto@horizon.com.br

(3) Instituto de Zootecnia (IZ), Centro de Nutrição e Alimentação Animal, Caixa Postal 60, CEP 13460-000 Nova Odessa, SP. E-mail: almb@dglnet.com.br, izabel@izsp.br

(4)IZ, Centro de Métodos Quantitativos. E-mail: eliana@izsp.br
}

mente nutritivo e digestivo, por dietas à base de cereais constitui-se no maior desafio na nutrição de suínos após o desmame (Aherne, 1990). Na alimentação do leitão desmamado, o milho e a soja são as principais fontes protéicas e energéticas de origem vegetal utilizadas. No entanto, como ocorre na forma natural, a presença do amido no milho e dos fatores antinutricionais (FAN) na soja desencadeiam distúrbios digestivos e sérios danos ao epitélio intestinal do leitão após o desmame (Shields Junior et al., 1980; Li et al., 1990). Tais efeitos prejudiciais, todavia, podem ser atenuados pelo cozimento, extrusão, micronização, irradiação e outros (Poel 
et al., 1989; Liener, 1994; Kaankuka et al., 1996). Não obstante, os resultados obtidos com o milho ou com a soja submetidos aos diversos tipos de processamentos são contraditórios.

Herkelman et al. (1990), avaliando a temperatura e o tempo de processamento entre o milho extrusado e o milho no estado natural verificaram que o método de extrusão permitiu aumento substancial na utilização de energia do milho por leitões desmamados. Moreira et al. (1994b) ao extrusarem o milho e utilizá-lo em rações fareladas não verificaram vantagens no desempenho de leitões entre 21 e 42 dias de idade. Resultados semelhantes foram constatados por Barbosa et al. (1999) em leitões com 6,5 kg de peso vivo, sugerindo que o baixo efeito do milho prégelatinizado poderia estar relacionado ao processamento inadequado na preparação do ingrediente.

Estudando alternativas para a substituição da proteína láctea em dietas destinadas a leitões desmamados aos 21 dias de idade, Li et al. (1990) observaram que o farelo de soja produzia efeitos deletérios no trato digestivo, com implicações negativas no desempenho. Por meio da extrusão, Friensen et al. (1993) constataram que a soja e subprodutos propiciaram desempenho dos leitões semelhante ao causado pelo farelo de soja. Utilizando método industrial, Sohn et al. (1994) concluíram que o processamento da soja integral permitiu aos leitões desmamados aos 21 dias de idade desempenho semelhante aos alimentados com produtos lácteos. Com o cozimento da soja integral, Kaankuka et al. (1996) obtiveram resultados satisfatórios em relação ao uso do farelo de soja nos leitões em idade de creche. Comparando diversas rações em leitões dos 21 aos 42 dias de idade, Barbosa et al. (1999) concluíram ser inviável a utilização de soja integral processadas a vapor e a seco, comparadas ao farelo de soja.

Além das implicações digestivas e fisiológicas no desdobramento do milho e da soja, a combinação das características dos ingredientes e o nível protéico da dieta são importantes fatores na alimentação do leitão pós-lactante. Contudo, os resultados e conclusões de diversos estudos com diferentes tipos de dietas e níveis protéicos em relação aos leitões desmamados são divergentes.

Assim, Harrison et al. (1989), Brudevold \& Soulthern (1994), Trindade Neto et al. (1994) e Hannas et al. (2000) observaram que o nível protéico da dieta pode afetar o desempenho do leitão, nos períodos subseqüentes ao desmame.

Combinando ingredientes na distinção entre dietas, Tokach et al. (1990), Lepine et al. (1991) e Mahan \& Newton (1993) verificaram que a inclusão acima de $25 \%$ dos produtos lácteos foi determinante na distinção dos resultados, quando avaliaram o desempenho de leitões após o desmame. Por sua vez, Trindade Neto et al. (1994), Berto et al. (1997), Carvalho (1998) e Mascarenhas et al. (1999) não observaram diferenças significativas com relação à mesma categoria de suínos ao incluírem níveis menores dos produtos.

O objetivo deste trabalho foi avaliar o efeito de dietas à base de milho e soja, processados de diferentes formas e com diferentes níveis de proteína, no desempenho de leitões.

\section{Material e Métodos}

Foram realizados dois experimentos na unidade de creche do Instituto de Zootecnia, em Nova Odessa, SP. Em cada experimento foram usados 80 leitões provenientes de cruzamentos entre reprodutores e matrizes comerciais, machos castrados e fêmeas, desmamados aos $20 \mathrm{e}$ 18 dias de idade, com respectivos pesos iniciais de $5,3 \pm 0,89 \mathrm{~kg}$ e $4,7 \pm 0,54 \mathrm{~kg}$, no primeiro e segundo experimentos, respectivamente.

O delineamento experimental usado, nos dois experimentos, foi o de blocos ao acaso, em esquema fatorial $2 \times 2$, com cinco repetições por tratamento e quatro animais por parcela. Os animais ficaram alojados em baias de 2,0x1,0 m, construídas em estrutura metálica, suspensas a $80 \mathrm{~cm}$ do chão, com piso de plástico vazado e comedouros semi-automáticos, localizadas em prédio de alvenaria com pé-direito de 3,4 m, janelas laterais do tipo vitral e três ventiladores para controlar o arejamento interno.

Os tratamentos constituíram-se de dois tipos de processamento de milho e de soja (como fonte protéica) no primeiro experimento, e de dietas com ou sem produtos lácteos e com dois níveis protéicos, no segundo experimento.

No primeiro experimento, foram utilizados o milho comum e o pré-gelatinizado, produto utilizado comercialmente na alimentação de leitões, e as fontes protéicas farelo de soja e soja integral macerada (imersão em água corrente por 12 horas). A soja integral macerada testada era de qualidade inferior e apresentava solubilidade protéica (66\%) abaixo dos padrões da Associação Nacional dos 
Fabricantes de Rações.

No segundo experimento, dietas à base de milho prégelatinizado e de soja integral macerada continham ou não produtos lácteos e eram formuladas com $15 \%$ e $18 \%$ de proteína bruta $(\mathrm{PB})$.

Os ingredientes empregados nas dietas foram analisados no Laboratório de Bromatologia do Instituto de Zootecnia, em Nova Odessa.

A soja integral macerada continha $20,41 \%$ de extrato etéreo (EE) e sua inclusão nas dietas permitiu níveis de EE superiores aos encontrados na literatura para as atividades enzimáticas no trato digestivo dos leitões nas fases de vida estudadas (Lindemann et al., 1986; Cera et al., 1988).

O palatabilizante continha $90 \%$ de matéria seca: $15,2 \%$ de PB, $3.420 \mathrm{kcal} / \mathrm{kg}$ de energia metabolizável (valor estimado), 0,54\% de Ca, 0,39\% de P total (Pt) e $0,12 \%$ de $\mathrm{P}$ disponível (Pd). As dietas do primeiro (Tabela 1) e do se- gundo experimento (Tabela 2) foram formuladas com base no National Research Council (1998), permitindo-se a deficiência marginal de alguns aminoácidos. Alimentação e água foram fornecidas à vontade em comedouros semiautomáticos e bebedouros do tipo chupeta.

No primeiro e no segundo experimento, o desmame ocorreu, respectivamente, no $20^{\circ}$ e $18^{\circ}$ dia de idade dos leitões. Determinações diárias de ganho de peso, ingestão de alimento e conversão alimentar foram realizadas em diferentes fases de desenvolvimento dos leitões: de 20 a 41 dias de idade (fase 1) de 42 a 55 dias (fase 2) e de 20 a 55 dias (fase total) no primeiro experimento; de 18 a 39 dias de idade (fase 1), de 40 a 53 dias (fase 2) e de 18 a 53 dias de idade (fase total) no segundo experimento. As análises estatísticas foram realizadas por meio do pacote computacional SAS (SAS Institute, 1996) e as médias comparadas pelo teste $\mathrm{F}$, conforme o modelo:

Tabela 1. Composição centesimal das dietas oferecidas aos leitões desmamados aos 20 dias de idade, dos 20 aos 41 dias de idade (fase 1) e dos 42 aos 55 dias de idade (fase 2) no primeiro experimento ${ }^{(1)}$.

\begin{tabular}{|c|c|c|c|c|c|c|c|c|}
\hline \multirow[t]{2}{*}{ Ingrediente (\%) } & \multicolumn{4}{|c|}{ Fase 1} & \multicolumn{4}{|c|}{ Fase 2} \\
\hline & MCFS & MPGFS & MCSIM & MPGSIM & MCFS & MPGFS & MCSIM & MPGSIM \\
\hline Milho comum & 63,90 & 0,00 & 58,54 & 0,00 & 69,50 & 0,00 & 64,40 & 0,00 \\
\hline Milho pré-gelatinizado & 0,00 & 62,20 & 0,00 & 58,00 & 0,00 & 67,70 & 0,00 & 62,00 \\
\hline Farelo de soja & 26,06 & 27,80 & 0,00 & 0,00 & 27,18 & 29,02 & 0,00 & 0,00 \\
\hline Soja integral macerada ${ }^{(2)}$ & 0,00 & 0,00 & 29,46 & 31,00 & 0,00 & 0,00 & 30,65 & 32,60 \\
\hline Palatabilizante & 6,00 & 6,00 & 6,00 & 6,00 & 0,00 & 0,00 & 0,00 & 0,00 \\
\hline Fosfato bicálcico & 1,93 & 1,93 & 1,84 & 1,84 & 1,48 & 1,48 & 1,38 & 1,38 \\
\hline Calcário calcítico & 0,60 & 0,60 & 0,73 & 0,74 & 0,67 & 0,68 & 0,81 & 0,82 \\
\hline L-lisina $\mathrm{HCl}$ & 0,512 & 0,460 & 0,456 & 0,404 & 0,230 & 0,175 & 0,141 & 0,083 \\
\hline DL-metionina & 0,174 & 0,160 & 0,159 & 0,142 & 0,040 & 0,025 & 0,025 & 0,008 \\
\hline Premix vitamina ${ }^{(3)}$ & 0,40 & 0,40 & 0,40 & 0,40 & 0,40 & 0,40 & 0,40 & 0,40 \\
\hline Premix mineral $^{(4)}$ & 0,10 & 0,10 & 0,10 & 0,10 & 0,10 & 0,10 & 0,10 & 0,10 \\
\hline Antibiótico $^{(5)}$ & 0,03 & 0,03 & 0,03 & 0,03 & 0,10 & 0,10 & 0,10 & 0,10 \\
\hline Sal & 0,28 & 0,30 & 0,28 & 0,28 & 0,30 & 0,30 & 0,30 & 0,30 \\
\hline Óleo de soja & 0,010 & 0,016 & 0,00 & 0,00 & 0,006 & 0,014 & 0,00 & 0,00 \\
\hline \multirow[t]{2}{*}{ Areia } & 0,00 & 0,00 & 2,00 & 1,06 & 0,00 & 0,00 & 1,69 & 2,21 \\
\hline & \multicolumn{8}{|c|}{ Composição calculada } \\
\hline Energia metabolizável (kcal/kg) & 3,269 & 3,268 & 3,336 & 3,336 & 3,265 & 3,268 & 3,376 & 3,326 \\
\hline Lactose $(\%)$ & 2,40 & 2,40 & 2,40 & 2,40 & 0,00 & 0,00 & 0,00 & 0,00 \\
\hline Proteína bruta (\%) & 18,00 & 18,02 & 18,00 & 18,01 & 18,00 & 18,00 & 18,00 & 18,00 \\
\hline Extrato etéreo $(\%)^{(6)}$ & 2,68 & 1,55 & 6,68 & 7,20 & 4,61 & 4,25 & 6,28 & 6,23 \\
\hline Cálcio (\%) & 0,80 & 0,80 & 0,80 & 0,80 & 0,70 & 0,70 & 0,70 & 0,70 \\
\hline Fósforo total (\%) & 0,67 & 0,66 & 0,68 & 0,67 & 0,60 & 0,58 & 0,61 & 0,60 \\
\hline Fósforo disponível (\%) & 0,40 & 0,40 & 0,40 & 0,40 & 0,32 & 0,32 & 0,32 & 0,32 \\
\hline Lisina digestível (\%) & 1,19 & 1,19 & 1,19 & 1,19 & 1,01 & 1,01 & 1,01 & 1,01 \\
\hline Metionina + cistina digestível $(\%)$ & 0,68 & 0,68 & 0,68 & 0,68 & 0,58 & 0,58 & 0,58 & 0,58 \\
\hline Triptofano digestível (\%) & 0,17 & 0,17 & 0,18 & 0,19 & 0,17 & 0,18 & 0,19 & 0,20 \\
\hline Treonina digestível $(\%)$ & 0,54 & 0,56 & 0,57 & 0,59 & 0,55 & 0,59 & 0,60 & 0,63 \\
\hline
\end{tabular}

(1)MCFS: milho comum e farelo de soja; MPGFS: milho pré-gelatinizado e farelo de soja; MCSIM: milho comum e soja integral macerada; MPGSIM: milho pré-gelatinizado e soja integral macerada. ${ }^{(2)}$ Atividade ureática: 0,02 ; solubilidade protéica em $\mathrm{KOH} 0,2 \%$ : 66,0; inibidor de tripsina UTI/mg de amostra e hemaglutinina $\mathrm{UH} / \mathrm{mg}$ amostra não encontrados. ${ }^{(3)}$ Quantidades/kg de ração: vitamina $\mathrm{A}, 9.000 \mathrm{UI}$; vitamina $\mathrm{D}_{3}, 1.800 \mathrm{UI}$; vitamina E, $18 \mathrm{mg}$; vitamina $\mathrm{K}_{3}, 1,2 \mathrm{mg}$; vitamina $\mathrm{B}_{1}, 1,4 \mathrm{mg}$; vitamina $\mathrm{B}_{2}, 4 \mathrm{mg}$; vitamina $\mathrm{B}_{6}, 1,4 \mathrm{mg}$; vitamina $\mathrm{B}_{12}, 18 \mu \mathrm{g}$; niacina, $30 \mathrm{mg}$; ácido pantotênico, $12 \mathrm{mg}$; ácido fólico, 0,4 mg; biotina, 0,1 mg; colina, $300 \mathrm{mg}$; promotor de crescimento, $76 \mathrm{mg}$; antibiótico, $66 \mathrm{mg}$; antioxidante, $100 \mathrm{mg}$. ${ }^{(4)}$ Quantidade/kg de ração: Fe, $80 \mathrm{mg}$; $\mathrm{Cu}, 12 \mathrm{mg} ; \mathrm{Mn}, 70 \mathrm{mg} ; \mathrm{Zn}, 100 \mathrm{mg} ; \mathrm{I}, \quad 1 \mathrm{mg} ; \mathrm{Se}, 0,12 \mathrm{mg}$. ${ }^{(5)}$ Oxitetraciclina na fase 1 e fosfato de tilosina na fase 2. ${ }^{(6)}$ Valores determinados no Laboratório de Bromatologia - IZ, Nova Odessa, SP. 
$Y_{i j k}=\mu+A_{i}+B_{j}+A_{i j}+C_{k}+e_{i j k}$

em que: $\mathrm{Y}_{\mathrm{ijk}}$ é a constante associada a todas as observações; $\mu$ é a média geral da variável; $A_{i}$ é o efeito do tipo de milho (experimento 1 ) ou da dieta (experimento 2 ) i, sendo $\mathrm{i}=1$ e $2 ; \mathrm{B}_{\mathrm{j}}$ é o efeito da fonte protéica (experimento 1) ou do nível protéico (experimento 2) $\mathrm{j}$, sendo $\mathrm{j}=1$ e 2; $\mathrm{AB}_{\mathrm{ij}}$ é o efeito da interação dos fatores i e j; $\mathrm{C}_{\mathrm{k}}$ é o efeito do bloco $\mathrm{k}$, sendo $\mathrm{k}=1,2, \ldots$ e $5 ; \mathrm{e}_{\mathrm{ijk}}$ é o erro aleatório associado a cada observação.

\section{Resultados e Discussão}

Em todas as fases do experimento 1 não houve interação $(\mathrm{P}>0,05)$ do tipo de milho e da fonte protéica nas variáveis de desempenho, contudo foram detectados efeitos principais do milho comum e do farelo de soja (Tabela 3 ).

Na fase 1 (20 aos 41 dias de idade), a presença do milho comum nas dietas permitiu aos leitões maior ganho de peso e maior consumo de ração, sem interferir na conversão alimentar, quando comparado ao milho pré-gelatinizado. Os efeitos do farelo de soja no ganho de peso, consumo de ração e conversão alimentar foram maiores do que os da soja integral macerada.

O milho comum e o farelo de soja também destacaram-se na fase 2 (42 aos 55 dias de idade), permitindo maior ganho de peso e consumo de ração, sem apresentar diferenças na conversão alimentar.

$\mathrm{Na}$ fase total de creche (desmame aos 55 dias de idade), o milho comum propiciou maior ganho de peso e consumo de ração do que o pré-gelatinizado; os leitões alimentados com farelo de soja apresentaram

Tabela 2. Composição centesimal das dietas oferecidas aos leitões desmamados aos 18 dias de idade, dos 18 aos 39 dias de idade (fase 1) e dos 40 aos 53 dias de idade (fase 2) no segundo experimento ${ }^{(1)}$.

\begin{tabular}{|c|c|c|c|c|c|c|c|c|}
\hline \multirow[t]{2}{*}{ Ingrediente (\%) } & \multicolumn{4}{|c|}{ Fase 1} & \multicolumn{4}{|c|}{ Fase 2} \\
\hline & CPL 18 & SPL 18 & CPL 15 & SPL 15 & CPL 18 & SPL 18 & CPL 15 & SPL 15 \\
\hline Milho pré-gelatinizado & 43,00 & 53,45 & 52,00 & 62,00 & 55,55 & 60,00 & 64,90 & 69,30 \\
\hline Soja integral macerada ${ }^{(2)}$ & 22,10 & 34,55 & 12,90 & 25,50 & 31,45 & 35,80 & 22,16 & 26,50 \\
\hline Leite em pó & 15,00 & 0,00 & 15,00 & 0,00 & 5,00 & 0,00 & 5,00 & 0,00 \\
\hline Soro de leite em pó & 10,00 & 0,00 & 10,00 & 0,00 & 5,00 & 0,00 & 5,00 & 0 \\
\hline Palatabilizante & 6,00 & 6,00 & 6,00 & 6,00 & 0,00 & 0,00 & 0,00 & 0,00 \\
\hline Fosfato bicálcico & 0,73 & 1,81 & 0,82 & 1,89 & 0,922 & 1,35 & 1,00 & 1,44 \\
\hline Calcário calcítico & 0,76 & 0,735 & 0,76 & 0,74 & 0,834 & 0,82 & 0,84 & 0,82 \\
\hline L-lisina $\mathrm{HCl}$ & 0,135 & 0,272 & 0,405 & 0,550 & 0,00 & 0,00 & 0,205 & 0,262 \\
\hline DL-metionina & 0,065 & 0,115 & 0,142 & 0,195 & 0,00 & 0,00 & 0,036 & 0,055 \\
\hline Premix vitamina ${ }^{(3)}$ & 0,40 & 0,40 & 0,40 & 0,40 & 0,40 & 0,40 & 0,40 & 0,40 \\
\hline Premix mineral $^{(4)}$ & 0,10 & 0,10 & 0,10 & 0,10 & 0,10 & 0,10 & 0,10 & 0,10 \\
\hline Antibiótico $^{(5)}$ & 0,04 & 0,04 & 0,04 & 0,04 & 0,10 & 0,10 & 0,10 & 0,10 \\
\hline Sal & 0,10 & 0,46 & 0,10 & 0,47 & 0,25 & 0,40 & 0,25 & 0,40 \\
\hline Areia & 1,57 & 2,04 & 1,33 & 2,11 & 0,39 & 1,03 & 0,00 & 0,62 \\
\hline & \multicolumn{8}{|c|}{ Composição calculada } \\
\hline Energia metabolizável (kcal/kg) & 3.274 & 3.320 & 3.270 & 3.360 & 3.380 & 3.381 & 3.340 & 3.337 \\
\hline Lactose $(\%)$ & 14,8 & 2,4 & 14,8 & 2,4 & 5,3 & 0,00 & 5,3 & 0,00 \\
\hline Proteína bruta (\%) & 18,00 & 18,00 & 15,00 & 15,03 & 18,00 & 18,01 & 14,99 & 15,00 \\
\hline Extrato etéreo $(\%)^{(6)}$ & 5,39 & 8,3 & 4,21 & 6,53 & 6,99 & 7,49 & 5,28 & 6,60 \\
\hline Cálcio (\%) & 0,80 & 0,80 & 0,80 & 0,80 & 0,70 & 0,70 & 0,70 & 0,70 \\
\hline Fósforo total (\%) & 0,60 & 0,68 & 0,60 & 0,66 & 0,58 & 0,61 & 0,55 & 0,58 \\
\hline Fósforo disponível (\%) & 0,40 & 0,40 & 0,40 & 0,40 & 0,32 & 0,32 & 0,32 & 0,32 \\
\hline Lisina digestível (\%) & 1,19 & 1,19 & 1,19 & 1,19 & 1,06 & 1,02 & 1,01 & 1,01 \\
\hline Metionina + cistina digestível $(\%)$ & 0,68 & 0,68 & 0,68 & 0,68 & 0,62 & 0,60 & 0,58 & 0,58 \\
\hline Triptofano digestível (\%) & 0,21 & 0,20 & 0,17 & 0,16 & 0,22 & 0,21 & 0,17 & 0,17 \\
\hline Treonina digestível (\%) & 0,71 & 0,64 & 0,59 & 0,52 & 0,67 & 0,66 & 0,58 & 0,55 \\
\hline
\end{tabular}

${ }^{(1)}$ CPL 18: dieta com produtos lácteos e 18\% de PB; SPL 18: dieta sem produtos lácteos e 18\% de PB; CPL 15: dieta com produtos lácteos e 15\% de PB; SPL 15: dieta sem produtos lácteos e $15 \%$ de PB; os produtos lácteos foram incluídos na proporção de $25 \%$ na fase 1 e de $10 \%$ na fase $2 .{ }^{(2)}$ Atividade ureática, 0,02 ; solubilidade protéica em KOH $0,2 \%, 66,0$; inibidor de tripsina UTI/mg de amostra e hemaglutinina UH/mg amostra não encontrados. ${ }^{(3)}$ Quantidade/kg de ração: vitamina $A, 9.000$ UI; vitamina $D_{3}, 1.350$ UI; vitamina $E, 18 \mathrm{mg}$; vitamina $K_{3}, 1,6 \mathrm{mg}$; vitamina $B_{1}, 1,4 \mathrm{mg}$; vitamina $B_{2}, 4 \mathrm{mg}$; vitamina $\mathrm{B}_{6}, 1,4 \mathrm{mg}$; vitamina $\mathrm{B}_{12}, 18 \mu \mathrm{g}$; niacina, $30 \mathrm{mg}$; ácido pantotênico, $12 \mathrm{mg}$; ácido fólico, $0,4 \mathrm{mg}$; biotina, $0,1 \mathrm{mg}$; colina, $300 \mathrm{mg}$; promotor de crescimento, $76 \mathrm{mg}$; antibiótico, $66 \mathrm{mg}$; antioxidante, $100 \mathrm{mg} .{ }^{\left({ }^{(}\right)}$Quantidade/kg de mistura: $\mathrm{Fe}, 80 \mathrm{mg} ; \mathrm{Cu}, 12 \mathrm{mg} ; \mathrm{Mn}, 70 \mathrm{mg} ; \mathrm{Zn}, 100 \mathrm{mg} ; \mathrm{I}, 1 \mathrm{mg} ; \mathrm{Se}, 0,12 \mathrm{mg} .{ }^{(5)} \mathrm{Oxitetraciclina}$ na fase 1 e fosfato de tilosina na fase 2. ${ }^{(6)}$ Valores determinados no Laboratório de Bromatologia - IZ, Nova Odessa, SP. 
melhor desempenho nas três variáveis (Tabela 3).

Resultados semelhantes foram obtidos por Moreira et al. (1994a) e Barbosa et al. (1999), com produtos de diferentes origens. Segundo Moreira et al. (1994a), na forma farelada as dietas com milho pré-cozido tornam-se pulverulentas, por causa da fina textura do produto, causando desconforto aos leitões, com prejuízo no consumo. O milho prégelatinizado, como fonte principal de energia em dietas fareladas, reduz o diâmetro geométrico médio (DGM) da mistura. Além da inclusão de óleo na ração para minimizar o problema (Moreira et al., 1994a), provavelmente, uma mudança na granulometria, mediante peletização, poderia favorecer o consumo das dietas com inclusão do milho pré-gelatinizado. Hongtrakul et al. (1998) ao avaliarem os efeitos do processo de extrusão em fontes de carboidratos constataram a formação de betaamilose e amilopectina cristalizada (retrogradação) que podem diminuir a habilidade das enzimas amilases na ruptura das ligações do amido. Nesse caso, além da menor conversão do amido em carboidratos solúveis, incluindo em glicose, há potencial perda dos aminoácidos (digestibilidade) e vitaminas. Concluíram que o processo de extrusão dos carboidratos tem diferentes efeitos no desempenho, e o grau de gelatinização pode não ser o fator principal na explicação dessas variações.

Além das respostas inferiores no desempenho dos leitões, outro fator inviável no uso do milho prégelatinizado em dietas fareladas é o seu custo, que é superior ao do milho.

Os piores resultados de desempenho dos leitões alimentados com soja integral macerada decorreram do processamento (temperatura e tempo) da soja utilizada. Entre as diversas amostras processadas, a estabilização da temperatura foi o fator principal na determinação da qualidade da soja integral macerada, o que ficou evidenciado no consumo das dietas, independentemente do tipo de milho. Moreira et al. (1994a) e Kaankuka et al. (1996) verificaram que as condições do processamento foram relevantes nos resultados de desempenho obtidos com leitões em fase de creche. Sohn et al. (1994) também verificaram uniformidade no processamento da soja integral por método industrial e que o desempenho dos leitões foi semelhante, após 21 dias de idade, ao compararem dietas que continham soja integral e produtos lácteos. Processada em menor quantidade, a soja integral apresentou resultados satisfatórios de

Tabela 3. Desempenho de leitões desmamados aos 20 dias de idade, submetidos a dietas contendo milho (comum e pré-gelatinizado) e fonte protéica (farelo de soja e soja integral macerada), de 20 a 41 dias de idade (fase 1), de 42 a 55 dias de idade (fase 2) e de 20 a 55 dias (fase total), no primeiro experimento ${ }^{(1)}$.

\begin{tabular}{lccccc}
\hline Variáveis & $\begin{array}{c}\text { Milho } \\
\text { comum }\end{array}$ & $\begin{array}{c}\text { Milho } \\
\text { pré-gelatinizado }\end{array}$ & Farelo de soja & $\begin{array}{c}\text { Soja integral } \\
\text { macerada }\end{array}$ & CV (\%) \\
\hline & & & Fase 1 & & \\
Ganho de peso (g/dia) & $323,7 \mathrm{a}$ & $260,5 \mathrm{~b}$ & $342,6 \mathrm{~A}$ & $241,6 \mathrm{~B}$ & 18,2 \\
Consumo de ração (g/dia) & $433,4 \mathrm{a}$ & $358,0 \mathrm{~b}$ & $435,8 \mathrm{a}$ & $355,6 \mathrm{~b}$ & 16,8 \\
Conversão alimentar & $1,35 \mathrm{a}$ & $1,42 \mathrm{a}$ & $1,26 \mathrm{~A}$ & $1,50 \mathrm{~B}$ & 10,1 \\
\hline & & & Fase 2 & & 5,3 \\
Ganho de peso (g/dia) & $618,7 \mathrm{~A}$ & $539,7 \mathrm{~B}$ & $626,4 \mathrm{~A}$ & $532,0 \mathrm{~B}$ & 12,3 \\
Consumo de ração (g/dia) & $864,7 \mathrm{~A}$ & $704,3 \mathrm{~B}$ & $852,6 \mathrm{~A}$ & $716,4 \mathrm{~B}$ & $1,35 \mathrm{a}$ \\
Conversão alimentar & $1,40 \mathrm{a}$ & $1,30 \mathrm{a}$ & $1,36 \mathrm{a}$ & & 12,0 \\
\hline & & & Fase total & & 7,9 \\
Ganho de peso (g/dia) & $441,7 \mathrm{~A}$ & $372,2 \mathrm{~B}$ & $456,2 \mathrm{~A}$ & $357,7 \mathrm{~B}$ & 13,1 \\
Consumo de ração (g/dia) & $605,8 \mathrm{~A}$ & $496,5 \mathrm{~B}$ & $602,4 \mathrm{~A}$ & $500,0 \mathrm{~B}$ & 6,3 \\
Conversão alimentar & $1,37 \mathrm{a}$ & $1,33 \mathrm{a}$ & $1,31 \mathrm{a}$ & $1,39 \mathrm{~b}$ & \\
\hline
\end{tabular}

${ }^{(1)}$ Médias seguidas de letras distintas, maiúsculas $(\mathrm{P}<0,01)$ ou minúsculas $(\mathrm{P}<0,06)$ na mesma linha, diferem entre si pelo teste $\mathrm{F}$; os dados representam médias de cinco repetições. 
digestibilidade, quando submetida a calor, após a maceração (Trindade Neto et al., 1998). No presente trabalho, a qualidade da soja após o processamento estava abaixo do padrão recomendado; os resultados da solubilidade protéica $(66 \%)$ indicaram redução na digestibilidade da soja integral macerada. Segundo Dale (1988), a solubilidade deveria estar entre $73 \%$ e $85 \%$ e valores abaixo desses caracterizariam o superaquecimento e, conseqüentemente, prejuízo no valor nutritivo do alimento.

Não obstante, outro fator que pode ter implicações negativas na ingestão e em decorrência no desempenho do leitão, é o teor lipídico da dieta com a substituição total do farelo pela forma integral da soja, conforme ocorreu no presente trabalho. A inclusão da soja integral macerada correspondeu, aproximadamente, a 7\% de óleo nas dietas. Cera et al. (1988) também constataram que o aumento da suplementação de óleo, até $6 \%$, em dietas para leitões desmamados aos 21 dias de idade, reduziu a retenção do $\mathrm{N}$ dietético. Os autores sugeriram que os efeitos negativos ocorreram, principalmente, nas duas semanas subseqüentes ao desmame, pela redução da área de absorção, quando o comprimento das vilosidades do jejuno permaneceu curto. Segundo Tokach et al. (1995), as características químicas dos ácidos graxos têm relação direta com as condições digestivas do leitão após o desmame, e a predominância de cadeias carbônicas longas prejudicam a digestão e utilização do óleo de soja.

No segundo experimento, também não houve interação $(\mathrm{P}>0,05)$ de tipo de dieta e nível protéico (Tabela 4).

Durante a fase 1 (18 aos 39 dias de idade), os leitões que receberam as dietas com produto lácteo e nível protéico de $18 \%$ apresentaram maior ganho de peso. Da mesma forma, observaram-se efeitos isolados dos fatores sobre o consumo e ração, destacando-se as dietas com produtos lácteos e $18 \%$ de PB. Quanto à conversão alimentar, os melhores resultados foram observados em relação aos leitões alimentados com as dietas com produtos lácteos, não detectando-se diferenças entre os níveis protéicos.

A presença dos produtos lácteos, bem como o nível de lactose, provavelmente, conferiu maior digestibilidade às dietas; $24 \%$ da energia metabolizável calculada provieram desses ingredientes. Além de melhorar a qualidade, as características organolépticas dos produtos lácteos podem ter favorecido o consumo dessas dietas, Lepine et al. (1991) concluíram que a inclusão de produtos lácteos, em nível desejável na dieta, permitiu melhorar a digestibilidade e, conseqüentemente, o desempenho dos leitões. Os aminoácidos presentes no leite em pó desnatado possuem digestibilidade superior aos correspondentes no farelo de soja e no milho (National Research Council, 1998).

Os resultados superiores dos leitões que receberam o nível dietético de $18 \%$ de $\mathrm{PB}$ refletiram o melhor ajuste dos aminoácidos dietéticos, considerando que apenas lisina e metionina foram suplementados. As dietas de baixa proteína (15\%), apresentaram déficits de triptofano e treonina, tomando-se por base a relação ideal sugerida pelo National Research Council (1998). Provavelmente, esse déficit teve implicações negativas no ganho de peso, pois os leitões alimentados com dietas de $15 \%$ de PB tiveram cerca de $85 \%$ do ganho de peso daqueles que receberam $18 \%$ de $\mathrm{PB}$. Associado ao pior desempenho estaria o déficit estimado em $25 \%$ do triptofano e da treonina [(composição média calculada das dietas sem produtos lácteos/exigência do National Research Council, 1998) x 100].

No transcorrer da fase 2 (40 aos 53 dias de idade), prolongou-se a eficácia das dietas com produtos lácteos, no aumento do ganho de peso e do consumo de ração. A conversão alimentar não foi afetada pela presença ou não de produtos lácteos, mas os leitões que consumiram as dietas com $15 \%$ de PB apresentaram melhor resultado. Considerando ser esta uma fase de aumento no consumo, a maior eficiência na utilização dos nutrientes, aferida como conversão alimentar, provavelmente, decorreu do menor teor lipídico nas rações com a redução do nível protéico. Em relação à inclusão da soja integral macerada, as dietas com $15 \%$ de PB tinham, em média, $28 \%$ a menos de teor lipídico. Na composição centesimal das dietas experimentais essa diferença correspondia a cerca de $2 \%$ de óleo. Segundo Tokach et al. (1995), nas condições fisiológicas digestivas do leitão nas fases de creche, o óleo de soja não é 
uma fonte energética desejável nas dietas afins.

A diferença entre os ganhos de peso dos leitões confirmou a vantagem em combinar ingredientes, verificando-se que as dietas com produtos lácteos tiveram um consumo de $22,4 \%$ a mais do que as dietas sem produtos lácteos. Não havendo diferenças na conversão alimentar, ficou caracterizado que o acréscimo na ingestão dessas dietas permitiu o maior ganho de massa corporal dos leitões submetidos aos tratamentos afins. Lepine et al. (1991) e Tokach et al. (1995) observaram que a presença e o nível de produtos lácteos nas dietas de leitões após o desmame têm implicações favoráveis nas fases subseqüentes às de creche.

Quanto ao nível protéico, com a redução das exigências nutricionais, não foram detectadas diferenças entre $18 \%$ e $15 \%$ no ganho de peso e consumo diário das dietas a partir dos 40 dias de idade. Provavelmente, a semelhança nas variáveis deveu-se ao baixo déficit médio calculado de triptofano (-5\%) e treonina (-7\%), permitindo que a conversão alimentar fosse melhor nas dietas com 15\% de PB. Esses resultados confirmam a sugestão de Trindade Neto et al. (1994) de redução do nível protéico se os aminoácidos em déficit fossem suplementados nas dietas para leitões desmamados aos 28 dias de idade. Fato comprovado por Carvalho (1998) ao utili- zar leitões desmamados aos 21 dias de idade.

$\mathrm{Na}$ fase total de creche (do desmame aos 55 dias de idade), confirmaram-se os efeitos da dieta quando a inclusão de produtos lácteos $(25 \%$ na fase $1 \mathrm{e}$ $10 \%$ na fase 2) permitiu aos leitões maior ganho de peso e consumo, sem diferenças na conversão alimentar. Os resultados confirmaram que a presença de produtos lácteos em níveis satisfatórios nas dietas após o desmame permite aos leitões benefícios significativos durante o período de creche, que pode se estender nas fases subsequientes (Lepine et al., 1991; Tokach et al., 1995; Trindade Neto et al., 1999).

O consumo diário de ração na fase total de creche foi maior com os leitões que receberam dietas com $18 \%$ de PB. Por causa da menor ingestão de ração, a melhor conversão alimentar ocorreu com os animais submetidos às dietas com $15 \%$ de PB. Com aumento do consumo de alimento na fase 2, provavelmente, o impacto do déficit de triptofano e treonina ocorrido na fase 1 foi minimizado, reduzindo-se as diferenças no desempenho quando foi considerada a fase total (55 dias de idade). Resultados semelhantes foram obtidos por Trindade Neto et al. (1994) e Carvalho (1998) ao compararem níveis protéicos que variavam de $16 \%$ a $20 \%$ em dietas de leitões desmamados na terceira e quarta semanas de

Tabela 4. Desempenho de leitões desmamados aos 18 dias de idade, submetidos a dietas com e sem produtos lácteos e com $18 \%$ e $15 \%$ de proteína bruta (PB), de 18 a 39 dias de idade (fase 1), de 40 a 53 dias (fase 2) e de 18 a 53 dias (fase total), no segundo experimento ${ }^{(1)}$.

\begin{tabular}{lccccc}
\hline Variáveis & $\begin{array}{c}\text { Com produtos } \\
\text { lácteos }\end{array}$ & $\begin{array}{c}\text { Sem produtos } \\
\text { lácteos }\end{array}$ & $18 \%$ de PB & $15 \%$ de PB & CV (\%) \\
\hline & & & Fase 1 & & \\
Ganho de peso (g/dia) & $268,8 \mathrm{~A}$ & $179,3 \mathrm{~B}$ & $241,6 \mathrm{~A}$ & $206,5 \mathrm{~B}$ & 11,4 \\
Consumo de ração (g/dia) & $371,4 \mathrm{~A}$ & $303,7 \mathrm{~B}$ & $360,0 \mathrm{a}$ & $315,1 \mathrm{~b}$ & 11,7 \\
Conversão alimentar & $1,39 \mathrm{~A}$ & $1,73 \mathrm{~B}$ & $1,52 \mathrm{a}$ & $1,60 \mathrm{a}$ & 17,6 \\
\hline & & & Fase 2 & & \\
Ganho de peso (g/dia) & $491,0 \mathrm{~A}$ & $399,5 \mathrm{~B}$ & $450,0 \mathrm{a}$ & $440,5 \mathrm{a}$ & 12,3 \\
Consumo de ração (g/dia) & $909,5 \mathrm{~A}$ & $706,1 \mathrm{~B}$ & $850,3 \mathrm{a}$ & $765,3 \mathrm{a}$ & 16,7 \\
Conversão alimentar & $1,86 \mathrm{a}$ & $1,77 \mathrm{a}$ & $1,89 \mathrm{~b}$ & $1,74 \mathrm{a}$ & 7,7 \\
\hline & & & Fase total & & \\
Ganho de peso (g/dia) & $402,2 \mathrm{~A}$ & $311,5 \mathrm{~B}$ & $366,8 \mathrm{a}$ & $346,9 \mathrm{a}$ & 11,5 \\
Consumo de ração (g/dia) & $586,7 \mathrm{~A}$ & $464,7 \mathrm{~B}$ & $556,1 \mathrm{a}$ & $495,3 \mathrm{~b}$ & 11,4 \\
Conversão alimentar & $1,46 \mathrm{a}$ & $1,50 \mathrm{a}$ & $1,52 \mathrm{~b}$ & $1,44 \mathrm{a}$ & 5,7 \\
\hline
\end{tabular}

${ }^{(1)}$ Médias seguidas de letras distintas, maiúsculas $(\mathrm{P}<0,01)$ ou minúsculas $(\mathrm{P}<0,05)$ na mesma linha, diferem entre si pelo teste $\mathrm{F}$; os dados representam médias de cinco repetições. 
idade.

\section{Conclusões}

1. As dietas que contêm produtos lácteos e as dietas com farelo de soja e milho comum propiciam desempenho superior de leitões, desmamados na terceira semana de idade.

2. O nível protéico de $18 \%$, em dietas com milho pré-gelatinizado e soja integral macerada, favorece o desempenho de leitões desmamados na terceira semana de idade.

\section{Agradecimento}

À Fapesp, pelo apoio financeiro.

\section{Referências}

AHERNE, J. A. El estrés nutricional, importante factor del rendimiento. International Pigletter, South St. Paul, v. 16, n. 5, p. 17-18, 1990.

BARBOSA, H. P.; TRINDADE NETO, M. A.; DE SORDI, I. M. P.; SCHAMMASS, E. A. Efeitos dos processamentos do milho comum e da soja integral no desempenho de leitões desmamados aos 21 dias de idade. Boletim de Indústria Animal, Nova Odessa, v. 56, n. 1, p. 59-66, 1999.

BERTO, D. A.; KRONKA, R. N.; THOMAZ, M. C.; KRONKA, S. N. Efeito do tipo de dieta e do sistema de alimentação na fase inicial sobre o desempenho de leitões. Revista Brasileira de Zootecnia, Viçosa, MG, v. 26 n. 1, p. 144-152, 1997.

BRUDEVOLD, A. B.; SOULTHERN, L. L. Low protein crystalline amino acid-supplemented, sorghum-soybean meal diets for the 10 to 20 kilogram pig. Journal of Animal Science, Champaign, v. 72, n. 3, p. 638-647, 1994.

CARVALHO, L. E. Desempenho de leitões recebendo na fase inicial diferentes níveis protéicos e tipos de dietas. 82 f. Tese (Doutorado em Zootecnia) - Universidade Estadual Paulista Júlio de Mesquita Filho, Jaboticabal, 1998.

CERA, K. R.; MAHAN, D. C.; REINHART, G. A. Effects of dietary dried whey and corn oil on weanling pig performance, fat digestibility and nitrogen utilization. Journal of Animal Science, Champaign, v. 66, n. 6, p. $1438-1445,1988$.

DALE, N. Solubilidad de la proteína: indicador del procesado de la harina de soya. Avicultura Profesional, Mount Morris, v. 5, n. 4, p. 122-126, 1988.

Pesq. agropec. bras., Brasília, v. 38, n. 3, p. 427-435, mar. 2003
FRIESEN, K. G.; NELSSEN, J. L.; GOODBAND, R. D. The effects of moist extrusion of soy products on growth performance and nutrient utilization in the early-weaned pig. Journal of Animal Science, Champaign, v. 71, n. 8, p. 2099-2109, 1993.

HANNAS, M. I.; OLIVEIRA, R. F. M.; DONZELE, J. L.; FERREIRA, A. S. Proteína bruta para suínos machos castrados mantidos em ambiente de conforto térmico dos 15 aos $30 \mathrm{~kg}$. Revista Brasileira de Zootecnia, Viçosa, MG, v. 29 , n. 2 , p. $476-484,2000$.

HARRISON, M. D.; CAMPBELL, D. R.; WALKER, W. R.; COMBA, G. E. Effects of dietary protein and crystalline lysine on performance of starting and finishing swine. Nutrition Report International, Los Altos, v. 39, n. 5, p. 1027-1036, 1989.

HERKELMAN, K. L.; HODHOUSE, S. L.; VEUM, T. L. Effects of extrusion on the ileal and fecal digestibilities of lysine in yellow corn in diets for young pigs. Journal of Animal Science, Champaign, v. 68, n. 8, p. 2414-2424, 1990.

HONGTRAKUL, K.; GOODBAND, R. D.; BEHNKE, K. C.; NELSSEN, J. L.; TOKACH, M. D.; BERGSTRÖM, J. R.; NESSMITH JUNIOR, W. B.; KIM, I. H. The effects of extrusion processing of carbohydrate sources on weanling pig performance. Journal of Animal Science, Champaign, v. 76, n. 12, p. 3034-3042, 1998.

KAANKUKA, F. G.; BALOGUN, T. F.; TEGBE, T. S. B. Effects of duration of cooking of full-fat soya beans on prodinate andysis, levels of antinutritional factors, and digestibility by weanling pigs. Animal Feed Science and Technology, Amsterdam, v. 62, n. 2/4, p. 229-237, 1996.

LEPINE, A. J.; MAHAN, D. C.; CHUNG, Y. K. Growth performance of weanling pigs fed corn-soybean meal diets with or without dried whey at various $\mathrm{L}$ lysine- $\mathrm{HCl}$ levels. Journal of Animal Science, Champaign, v. 69, n. 5, p. 2026-2032, 1991.

LI, F. D.; NELSSEN, J. L.; REDDY, P. G. Transient hypersensitivity to soybean meal in the early-weaned pig. Journal of Animal Science, Champaign, v. 68, n. 6, p. 1790-1799, 1990

LIENER, I. E. Implications of antinutritional components in soybeans foods. Critical Reviews in Food and Science and Nutrition, West Palm Beach, v. 34, n. 1, p. 31-67, 1994.

LINDEMANN, M. D.; CONELIUS, S. G.; EL KANDELGY, S. M.; MOSER, R. L.; PETTIGREW, J. Effect of age, weaning and diet on digestive enzyme levels 
in the piglet. Journal of Animal Science, v. 62, n. 5, p. $1298-1307,1986$.

MAHAN, D. C.; NEWTON, E. A. Evaluation of feed grains with dried skim milk and added carbohydrate sources on wealing pig performance. Journal of Animal Science, Champaign, v. 71, n. 12, p. 3376-3382, 1993.

MASCARENHAS, A. G.; FERREIRA, A. S.; DONZELE, J. L.; FREITAS, R. T. F.; GOMES, P. C.; OLIVEIRA, R. F. M. Avaliação de dietas fornecidas dos 14 aos 42 dias de idade sobre o desempenho e a composição de carcaça de leitões. Revista Brasileira de Zootecnia, Viçosa, MG, v. 28, n. 6 , p. 1319-1326, 1999.

MOREIRA, I.; ROSTAGNO, H. S.; TAFURY, M. L.; COSTA, P. M. Uso da soja processada a calor na alimentação de leitões de 21 a 42 dias de idade. Revista Brasileira de Zootecnia, Viçosa, MG, v. 23, n. 1, p. 57-64, 1994a.

MOREIRA, I.; ROSTAGNO, H. S.; TAFURY, M. L.; COSTA, P. M. Uso do milho processado a calor na alimentação de leitões. Revista Brasileira de Zootecnia, Viçosa, MG, v. 23, n. 3, p. 412-421, 1994b.

NATIONAL RESEARCH COUNCIL (Washington, Estados Unidos). Nutrients requirements of swine. 10th ed. Washington: National Academy of Science, 1998. 189 p.

POEL, A. F. B van der; HARTOG, L. A. den; ABEELE, T. H. van den. Effect of infrared irradiation or extrusion processing of maize on its digestibility in piglets. Animal Feed Science and Technology, Amsterdam, v. 26, n. 1/2, p. 29-43, 1989.

SAS INSTITUTE (Cary, Estados Unidos). SAS user's guide: statistics: release 6.12. Cary, 1996. 943 p.

SHIELDS JUNIOR, R. G.; EKSTROM, K. E.; MAHAN, D. C. Effect of weaning age and feeding method on digestive enzyme development in swine from birth to ten weeks. Journal of Animal Science, Champaign, v. 50, n. 2, p. 257-265, 1980.

SOHN, K. S.; MAXWELL, C. V.; BUCHANAN, D. S. Improved soybean protein sources for early-weaned pigs: effects on performance and total tract amino acid digestibility. Journal of Animal Science, Champaign, v. 72, n. 3, p. 622-630, 1994.

TOKACH, M. D.; PETTIGREW, J. E.; JOHNSTON, L. J.; CORNELIUS, S. G. Effect of adding fat and (or) milk products to the weanling pig diet on performance in nursery and subsequent grow-finishing stages. Journal of Animal Science, Champaign, v. 73, n. 12, p. 3358-3368, 1995.

TOKACH, M. D.; PETTIGREW, J. E.; JOHNSTON, L. J.; CORNELIUS, S. G. Overall pig performance to market weight improved by adding milk products, but not fat, to the initial diet. Journal of Animal Science, Champaign, v. 68 , n. 2 , p. 377-378, 1990. Supplement 1.

TRINDADE NETO, M. A.; BARBOSA, H. P.; DE SORDI, I. M. P.; CHAMMASS, E. A. Dietas contendo milho pré-gelatinizado e níveis protéicos para leitões desmamados aos 19 dias de idade. In: REUNIÃO ANUAL DA SOCIEDADE BRASILEIRA DE ZOOTECNIA, 36. 1999, Porto Alegre. Anais... Porto Alegre: Sociedade Brasileira de Zootecnia, 1999. CD-ROM. Seção nutrição de não-ruminantes- suínos-FOR-084.

TRINDADE NETO, M. A.; BARBOSA, H. P.; DE SORDI, I. M. P.; CHAMMASS, E. A. Digestibilidade e valores energéticos da soja integral submetida a maceração e processamento térmico para suínos. In: REUNIÃO ANUAL DA SOCIEDADE BRASILEIRA DE ZOOTECNIA, 35., 1998, Botucatu. Anais... Botucatu: Sociedade Brasileira de Zootecnia, 1998. p. 445-447.

TRINDADE NETO, M. A.; LIMA, J. A. F.; BETERCHINI, A. G.; OLIVEIRA, A. I. Dietas e níveis protéicos para leitões desmamados aos 28 dias de idade: fase inicial. Revista Brasileira de Zootecnia, Viçosa, MG, v. 23, n. 1, p. 92-99, 1994. 